\title{
mTOR inhibitors in the pharmacologic management of tuberous sclerosis complex and their potential role in other rare neurodevelopmental disorders
}

\author{
David N. Franz ${ }^{1 *}$ and Jamie K. Capal ${ }^{2}$
}

\begin{abstract}
Tuberous sclerosis complex (TSC) is a rare autosomal dominant genetic disorder that affects multiple organ systems throughout the body. Dysregulation of the mammalian target of rapamycin (mTOR) pathway is implicated in the disease pathology, and evidence exists to support the use of mTOR inhibitors in treatment. The mTOR pathway has also been investigated as a potential treatment target for several other rare diseases. TSC research has highlighted the value of pursuing targeted therapies based on underlying molecular pathophysiology. One goal of current research is to identify the role of mTOR inhibition in neurologic and developmental disorders apart from TSC. There is also particular interest in the potential role of mTOR inhibitors in preventing seizures, neurodevelopmental disabilities, renal tumors, cutaneous tumors, and other manifestations typically seen in TSC. It is foreseeable that use of mTOR inhibition to prevent long-term morbidity in TSC will become mainstream therapeutic practice. This review will provide an overview of the relationship between the mTOR pathway and TSC disease pathology, summarize the clinical evidence supporting the use of mTOR inhibitors for treatment of the various manifestations of TSC, and discuss the potential therapeutic role of mTOR inhibitors in several rare diseases.
\end{abstract}

Keywords: Hamartomas, Morbidity, Mammalian target of rapamycin inhibitors, Neurologic manifestations, Tuberous sclerosis complex

\section{Background}

Tuberous sclerosis complex (TSC) is an autosomal dominant genetic disorder that typically results in the growth of hamartomas in multiple major organ systems [1-3]. TSC is a rare disease that is estimated to occur in one in 6000 births, affecting approximately 1.5 million people worldwide $[1,2,4]$. Although TSC can manifest in many organs to different degrees of severity, it is primarily characterized by neurologic manifestations (including seizures); neurodevelopmental disabilities (e.g., intellectual disability and autism); and lesions in the brain, lungs, kidneys, and skin [1]. Updated TSC consensus recommendations established in 2012 now recommend

\footnotetext{
* Correspondence: David.Franz@cchmc.org

${ }^{1}$ Department of Pediatrics, Tuberous Sclerosis Clinic, Cincinnati Children's Hospital Medical Center, University of Cincinnati College of Medicine, Cincinnati, OH, USA

Full list of author information is available at the end of the article
}

the use of systemic treatment with mammalian target of rapamycin (mTOR) inhibitors in certain cases, which provides an opportunity to treat multiple manifestations of TSC simultaneously [5]. This review evaluates the current role of and available clinical data on MTOR inhibitor use in TSC and discusses potential future roles for mTOR inhibitors in TSC and similar diseases that are currently under investigation.

\section{Materials and methods}

We conducted a search of the published literature on PubMed/Medline for, and participated in, key clinical studies of mTOR inhibitors in treating subependymal giant cell astrocytomas (SEGAs), angiomyolipomas, lymphangioleiomyomatosis (LAM), angiofibromas, and epilepsy in patients with TSC. For other rare diseases, the terms "mTOR", "mTOR inhibitor", and "mTOR 
inhibition" were used in individual searches for "Leigh syndrome", "Down syndrome", and "Neurofibromatosis".

\section{Manifestations associated with TSC}

Cortical tubers, subependymal nodules (SENs), and SEGAs are the primary abnormalities found in the brain [1]. Cortical tubers, which are formed during embryogenesis, can be present at birth and have been observed in $80 \%$ to $90 \%$ of patients with TSC $[1,2,6]$. Tubers are thought to be associated with the development of seizures, intellectual disability, behavioral difficulties, and autism [6, 7]. SENs, which are asymptomatic hamartomas that protrude into the ventricles of the brain, occur in approximately $90 \%$ of individuals, and in about $5 \%$ to $20 \%$ of individuals they can develop into SEGAs $[1,8]$. SEGAs are slow-growing glioneuronal tumors that develop near the foramen of Monro and have the potential to cause hydrocephalus, increased intracranial pressure, and death secondary to impeded ventricular cerebrospinal fluid flow $[1,6]$. Prior to the use of pharmacologic therapy to reduce tumor volume, treatment for growing, symptomatic SEGAs has been mainly surgical resection $[9,10]$.

In the central nervous system, epilepsy is the most common medical disorder in patients with TSC, affecting up to $96 \%$ of individuals $[11,12]$. Focal seizures and infantile spasms are the most common seizure types in patients with TSC. Infantile spasms are common during infancy (i.e., first year of life), occurring in up to one-third of children with TSC $[10,11]$. Early onset of infantile spasms is associated with poor developmental outcomes and worse future seizure control $[1,13,14]$.

TSC involves multiple organ systems, including the brain, kidneys, lungs, heart, and skin. Renal manifestations occur in approximately $55 \%$ to $90 \%$ of patients with TSC, with angiomyolipomas occurring in up to $75 \%$ of patients [6]. Renal angiomyolipomas are the most common cause of mortality in patients with TSC because of potential renal failure or hemorrhage [15]. LAM is the most common lung manifestation in TSC, characterized by development of cystic lesions in the lung. LAM can occur in patients with TSC but can also occur sporadically in non-TSC individuals [16]. LAM occurs in approximately $30 \%$ to $40 \%$ of patients with TSC, is seen almost exclusively in women, and can lead to destruction of lung parenchyma, resulting in progressive dyspnea on exertion and recurrent pneumothorax [1618]. Cardiac rhabdomyomas are a common initial manifestation of TSC and occur in 33\% of patients. Rhabdomyomas are typically asymptomatic and spontaneously regress with age $[19,20]$; however, in rare instances, the location of the tumor can cause arrhythmia and heart failure [21]. Most patients (> 90\%) exhibit skin manifestations, including hypomelanotic macules (ash leaf spots), angiofibromas and/or cephalic plaques, ungual or periungual fibromas, shagreen patches, and confetti skin lesions. Angiofibromas are present in approximately $80 \%$ of individuals with TSC older than the age of 5 years, and typically develop on the face [3]. The characteristic red or pink nodules often develop within the first few years of life and become more pronounced with age [22]. Although multiple dermatologic treatments exist (including surgical excision in some cases), fibroma often recurs [22].

\section{mTOR pathway in the pathogenesis of TSC}

In normal cells, the mTOR signaling cascade (also known as the phosphatidylinositol 3-kinase [PI3K]/protein kinase B [Akt]/mTOR pathway) plays an important role in cell growth, proliferation, and survival (Fig. 1) [23]. Stimulants, such as growth factors (e.g., insulin-like growth factor-1 [IGF-1]), bind to tyrosine kinase receptors (e.g., IGF-1R), which leads to the phosphorylation of PI3K [23]. This activation of PI3K results in a cascade of phosphorylation events, resulting in the activation of Akt, which in turn inhibits the TSC1/TSC2 complex, which negatively regulates mTOR by acting as a GTPase-activating protein toward Ras homolog enriched in brain (Rheb), a direct and positive regulator of mTOR. As a result, inhibition of the TSC1/TSC2 complex results in the overactivation of mTOR, leading to cell growth and proliferation [23-25]. Two additional proteins, the NF1-encoded neurofibromin and the NF2encoded Merlin, also act as negative regulators of the mTOR pathway [26, 27]. mTOR forms two distinct multiprotein complexes, mTORC1 and mTORC2, which are differentiated by their interaction partners (regulatory associated protein of mTOR [RAPTOR] for mTORC1 and rapamycin-insensitive companion of mTOR [RICTOR]/ SIN1 for mTORC2), substrate selectivity, and sensitivity to rapamycin (sirolimus) and its analogs (e.g., everolimus) $[25,28]$. The downstream effects of mTORC1 include gene transcription and protein translation, cell proliferation and survival, and angiogenesis, while mTORC2 is thought to mediate cytoskeletal dynamics [28]. Dysregulation of the mTOR pathway has been implicated in the development of many cancers, including TSC, along with other neurologic disorders [23, 28].

TSC is caused by a mutation in either the TSC1 or the TSC2 gene, the loss of which triggers constitutive activation of the mTOR signaling pathway, leading to abnormal cell growth/proliferation and the subsequent formation of hamartomatous lesions $[25,29]$. The discovery of the relationship between TSC1/TSC2 and mTOR has resulted in important clinical advances in the use of mTOR inhibitors, particularly sirolimus and its analog everolimus, for the treatment of several TSC manifestations. Sirolimus and everolimus both work by binding to and forming a 


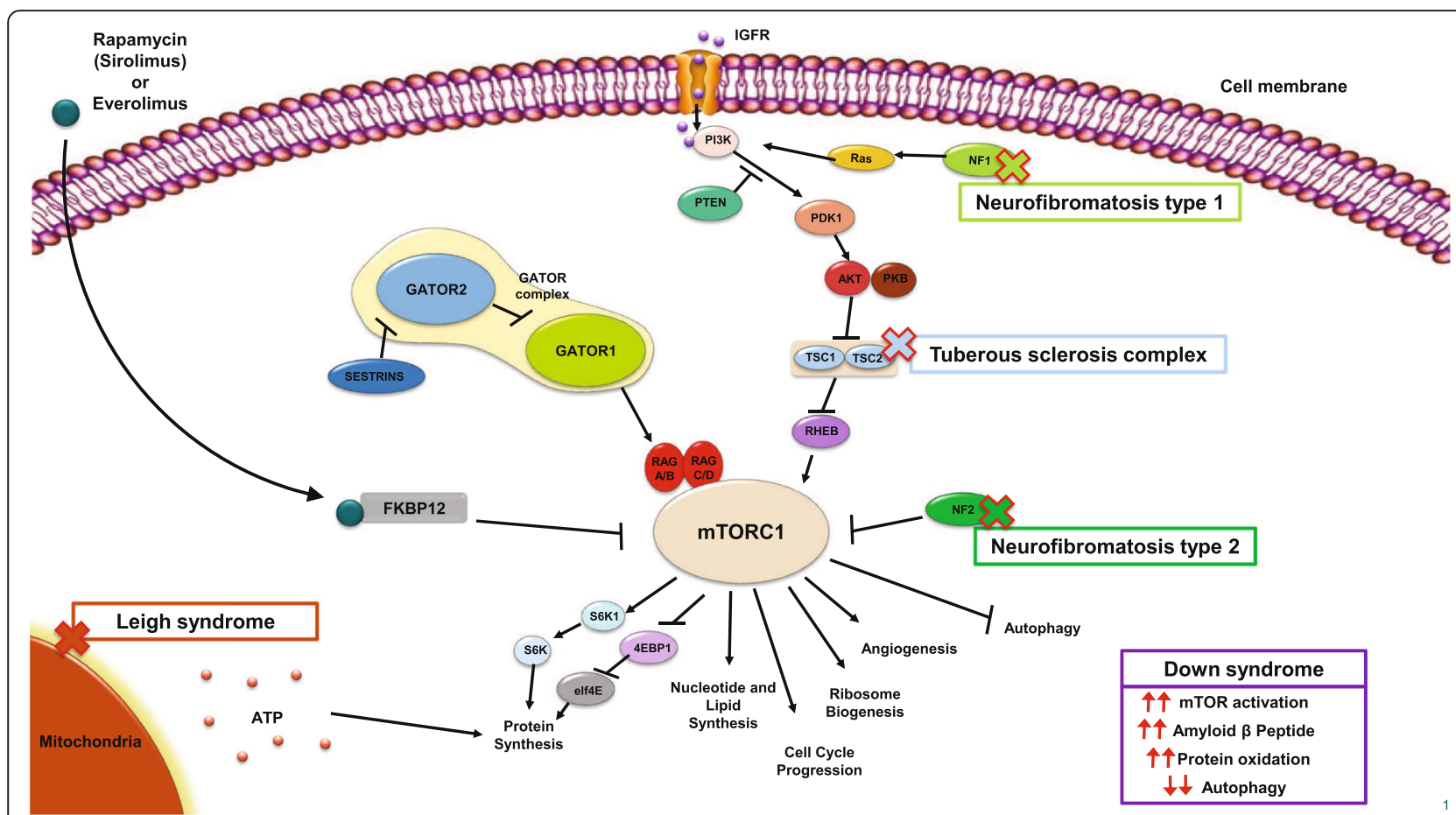

Fig. 1 The mammalian target of rapamycin (mTOR) signaling pathway and possible involvement of rare diseases in the pathway. Stimulants such as insulin-like growth factor bind to tyrosine kinase receptors, which leads to the phosphorylation of phosphatidylinositol 3-kinase (PI3K) [23]. A cascade of subsequent phosphorylation events results in the activation of protein kinase B (AKT), which in turn phosphorylates and inhibits the TSC1/TSC2 complex, a negative regulator of mTOR that is directed against the positive regulator Ras homolog enriched in brain (Rheb). As a result, inhibition of the TSC1/TSC2 complex results in the activation of mTOR [23-25]. NF1-encoded neurofibromin and NF2-encoded Merlin proteins also act as negative regulators of the mTOR pathway. Neurofibromin functions as a Ras-GTPase activating protein that inhibits the actions of Ras on PI3K [26], while Merlin acts directly on mTOR complex 1 (mTORC1) [27]. Sirolimus and everolimus both bind to and form complexes with FK506-binding protein-12 (FKBP12), resulting in the inhibition of mTORC1 activity [24]. While mechanisms are complex and not fully clear in Leigh and Down syndrome, evidence has shown a relationship between mTOR activity and ATP (Leigh syndrome), and decreased autophagy with increased protein production and oxidation with mTOR hyperactivation (Down syndrome) $[62,65,66]$

complex with FK506-binding protein-12 (FKBP12) which then inhibits mTORC1 (Fig. 1) [24].

\section{mTOR inhibitors for the management of TSC- associated manifestations \\ TSC-associated SEGA}

Experience with sirolimus in treating SEGA was evaluated in case reports and as a secondary end point in a phase two trial with a small number of patients. In these cases, sirolimus demonstrated an observable regression of SEGA lesions [30-32].

Everolimus has been studied more extensively in treating SEGA through long-term phase 2 and 3 studies [33-36]. In a 6-month open-label phase 2 study consisting of 28 patients, everolimus demonstrated a significant reduction in tumor volume compared with baseline, with approximately $75 \%$ of patients experiencing a $\geq 30 \%$ reduction in SEGA volume and $32 \%$ experiencing $\mathrm{a} \geq 50 \%$ reduction [33]; these reductions were sustained during the extension phase of the trial (median 5.65 years of treatment) [37]. In a randomized, double-blind, placebo-controlled, phase 3 study of 117 patients with SEGA associated with TSC, treatment with everolimus (median 9.6 months) was associated with a significantly higher SEGA response $(\geq 50 \%$ reduction of SEGA volume) rate compared with placebo (35\% vs. 0\%; $p<.0001)$ [35]. An analysis of 111 patients who received at least one dose of everolimus (in either the double-blind or a subsequent open-label phase) revealed that SEGA response increased to $57.7 \%$ over a median duration of 47.1 months (3.9 years), and the median reduction in SEGA volume was maintained, and even slightly increased, over the duration of the study [38]. Taken together, phase 2 and 3 clinical data on everolimus supported its use in the setting of TSC-associated SEGA, with the phase 2 results leading to the US Food and Drug Administration (FDA) approval of everolimus for the treatment of SEGA in pediatric and adult patients with TSC [39].

\section{TSC-associated renal angiomyolipoma}

Everolimus was evaluated for the management of renal angiomyolipoma in the large phase 3 EXIST-2 trial and in a subset of the patients from the EXIST-1 trial who 
had SEGA and renal angiomyolipoma [40, 41]. In EXIST-2, the angiomyolipoma response rate $(\geq 50 \%$ reduction in volume in absence of other factors) after approximately 8 months of treatment was $42 \%$ for patients taking everolimus compared with $0 \%$ in patients receiving placebo $(p<.0001)$ [40], which increased to $54 \%$ in patients treated with everolimus for a median of 29 months [42], and $58 \%$ at the completion of the openlabel extension phase (median exposure, 46.9 months) [43]. Based on the results from the core phase of EXIST2, everolimus was approved by the FDA for the treatment of adult patients with renal angiomyolipoma and TSC [39]. Similar to the findings of EXIST-2, a subset of patients with SEGA and angiomyolipoma in EXIST-1 (largely pediatric population) reported angiomyolipoma response rates of $53.3 \%$ for everolimus and $0 \%$ for placebo after a median of 9.6 and 8.3 months of treatment, respectively; $80 \%$ of patients achieved a $\geq 50 \%$ reduction in renal angiomyolipoma volume after 48 weeks (11 months) of treatment [41].

Sirolimus has not been approved for the management of renal angiomyolipoma, but has been evaluated in several small open-label phase 2 clinical studies [32, 44-46]. Bissler et al. found that sirolimus reduced the size of angiomyolipoma lesions and improved lung function over 12 months of treatment [44]. However, 12 months after sirolimus was discontinued, lesion size and several lung function parameters approached baseline levels, suggesting that therapy with mTOR inhibition might necessitate long-term or indefinite use [44]. Davies et al. conducted a longer study and found that $50 \%$ of patients reported a positive angiomyolipoma response (disappearance of lesions or $\geq 30 \%$ reduction in sum of longest diameter of target lesions) over a 2-year period [45]. One phase 2, multicenter trial of sirolimus in adults with TSC evaluated the effects of sirolimus on multiple lesion types. Over a period of 1 year of treatment, they observed reductions in renal angiomyolipoma size, SEGA size, and liver angiomyolipoma size, with subjective improvement in skin lesions and reduction of vascular endothelial growth factor (VEGF) D [32].

\section{TSC-associated LAM}

Sirolimus and everolimus have both been evaluated for the management of LAM in a number of studies consisting primarily of patients with sporadic LAM, although small numbers of patients with TSC-associated LAM were also included [47-50]. In the multicenter placebocontrolled MILES study, 89 patients with LAM (8 with a codiagnosis of TSC) receiving treatment with sirolimus $(n=46)$ over 12 months exhibited improvements in forced vital capacity (FVC) and quality of life, as well as stabilization of forced expiratory volume in 1 second $\left(\mathrm{FEV}_{1}\right)$ [47]. These findings led to the FDA approval of sirolimus for the treatment of LAM [51]. Two retrospective studies also evaluated sirolimus in treating LAM [48, 49], reporting improved or stabilized lung function even at serum trough levels $<5 \mathrm{ng} / \mathrm{mL}$ [48], along with sustained effects over a treatment period of approximately 3.5 years [49].

Recently, everolimus was evaluated in a prospective study that included 24 patients (5 with TSC-LAM) and showed improvements in $\mathrm{FEV}_{1}$, stabilization of $\mathrm{FVC}$, and reductions in VEGF-D and collagen IV; however, optimal dosing of everolimus for this indication needs further investigation [50]. As a result, everolimus has yet to receive approval for use in the LAM setting.

\section{TSC-associated seizures}

Although no mTOR inhibitors are currently indicated specifically for the treatment of seizures associated with TSC, recent clinical evidence has shown promise for this use in this setting. The results of several small reports suggest that sirolimus may be effective for the treatment of TSC-associated seizures [52-54]. Sirolimus therapy given over 10 months in a 10 -year-old girl reduced daily seizure activity from 5-10 times/day to 1-5 times/day and resulted in the cessation of seizure clusters [52]. A case series of seven children with TSC found that all patients experienced seizure control after 12 months of treatment with sirolimus [53]. A second case series of seven children with TSC and refractory seizures reported that most patients had $50 \%$ to $90 \%$ reductions in numbers of seizures [54]. In a recent, small, randomized trial of 23 children (ages 3 months to 12 years) with TSC, treatment with sirolimus decreased overall seizure frequency $41 \%$ over standard of care, but this change failed to reach statistical significance $(p=.11)$ [55].

Use of everolimus in TSC-associated refractory seizures has also been evaluated [33, 56]. A prospective, phase $1 / 2$ trial directly evaluating everolimus in managing refractory seizures associated with TSC showed a reduction in seizure frequency of $\geq 50 \%$ in 12 of 20 patients after 12 weeks of treatment [56]. In a phase 2 study, everolimus therapy was associated with a clinically relevant reduction in the overall frequency of clinical and subclinical seizures (median change, -1 seizure; $p=.02$ ) in patients with SEGA. Of the 16 patients for whom electroencephalographic data were available, seizure frequency decreased in nine patients after 6 months; five additional patients did not experience an event [33]. Results from the first phase 3 study to evaluate an mTOR inhibitor (everolimus) for refractory seizures associated with TSC were recently reported (ClinicalTrials.gov NCT01713946) [57]. This prospective, randomized, double-blind, multicenter study compared everolimus at two different trough levels (low exposure, 3-7 ng/mL; high exposure, 9-15 ng/ $\mathrm{mL})$ with placebo in reducing seizures $(N=366)$ when 
added to an existing antiepileptic drug regimen. After 18 weeks of treatment, the median percentage reduction in seizure frequency was significantly higher with everolimus (29.3\% for everolimus low exposure and 39.6\% for everolimus high exposure compared with $14.9 \%$ with placebo [ $p=.0028$ and $p<.0001$, respectively]), and the proportion of responders ( $\geq 50 \%$ reduction in seizure frequency) was significantly greater with everolimus $(28.2 \%$ for everolimus low exposure and $40 \%$ for everolimus high exposure compared with $15.1 \%$ with placebo $[p=.0077$ and $p<.0001$, respectively]) [57]. These preliminary findings indicate that adjunctive treatment with everolimus may be an effective option in reducing refractory seizures in patients with TSC.

\section{TSC-associated neuropsychiatric disorders (TAND)}

mTOR inhibitors may also be a rational candidate for the management of neurodevelopmental/neuropsychiatric disabilities associated with TSC, including intellectual disability and autism. Indeed, a recent preclinical study of adult rats with TSC2 mutations and developmental status epilepticus, and a case study of a patient with TSC both reported improvements in social deficit behaviors, including autism-related behaviors, following mTOR inhibitor therapy with everolimus $[58,59]$. However, mTOR inhibitors have not been adequately evaluated or approved for the treatment of neurodevelopmental disabilities in TSC, especially in young infants. It is also essential that we establish the safety and overall impact of mTOR inhibitors in the pediatric population before larger, definitive clinical trials can be pursued. In the future, we await further information on effects of mTOR inhibitors on TSC-associated neuropsychiatric disorders, including secondary analyses from EXIST-3, and results from several phase 2 trials (NCT01289912, NCT01954693).

\section{Rationale for potential use of mTOR inhibitors in other novel indications}

In addition to TSC, mTOR inhibition is being explored in other rare diseases for which mTOR dysregulation has been noted.

\section{Leigh syndrome}

In Leigh syndrome, genetic defects result in disruption of mitochondrial function, which contributes to numerous health problems. Patients can have symptoms such as respiratory abnormalities, ocular and other cranial nerve palsies, involuntary movements, motor delays, intellectual disabilities, and seizures [60]. Although the time of onset can vary, it typically occurs in the first year of life. Leigh syndrome is characterized by diffuse multifocal spongiform degeneration in various parts of the brain, and many patients die within a few years after symptom onset [60].
In a preclinical study with $N d u f s 4$ knockout mice (the protein product of the Ndufs 4 gene is involved in the assembly, stability, and activity of complex I of the mitochondrial electron transport chain), rapamycin administration increased survivability and health [61]. The mechanism behind this is not entirely understood; however, it is believed that reduction of mTOR activity may shift cell metabolism toward amino acid catabolism and away from glycolysis and, thus, reduce the buildup of glycolytic intermediates that are associated with Leigh syndrome [61].

Additional research has suggested mTOR inhibition may aid in Leigh syndrome through preservation of adenosine triphosphate (ATP). Mitochondria provide energy to the cell through ATP, which has been found to be decreased in mitochondrial disorders; this leads to the degeneration of neurons, as in Leigh syndrome [62]. In an in vitro study, rapamycin was introduced to neuronal cells with mitochondrial defects, resulting in a significant rise in ATP level while protein production slowed [62]. It is theorized that the decrease in the energyconsuming process of protein synthesis with mTOR inhibition allows for more ATP to be spared [62].

Although investigation into the use of mTOR inhibitors in Leigh syndrome is at a very early stage, preclinical results are promising because there are currently no effective therapies for this disease.

\section{Down syndrome}

Down syndrome is a genetic disorder associated with intellectual disability caused, in most cases, by trisomy of human chromosome 21 [63]. Down syndrome is characterized by abnormalities in dendritic morphology and synaptic plasticity, and mTOR is believed to be involved in the growth and branching of dendrites in the hippocampus [64]. The mTOR activity of dendrites in the hippocampus has been shown to be increased in a mouse model of Down syndrome [64]. This increase was subsequently reversed after administration of rapamycin. Studies are underway to investigate whether rapamycin can reverse learning deficits associated with Down syndrome.

Hyperactivation of the PI3K/Akt/mTOR pathway was also observed in autopsy samples of patients with Down syndrome compared with controls [65]. A causative factor of Down syndrome is hypothesized to be the triplication of amyloid-beta protein gene, resulting in excess protein proliferation. In combination with decreased autophagy as a result of increased mTOR activation, this may result in the accumulation of amyloid beta peptide in the brain and contribute to the neurodegenerative process and to eventual Alzheimer's-like dementia in these patients [65]. Oxidative stress is also believed to have a role in neurodegenerative diseases such as Down syndrome. A mouse model of Down syndrome demonstrated that protein oxidation was increased possibly due 
to the decreased protective effect of autophagy as a result of mTOR pathway hyperactivation [66]. Signs of protein oxidation in cells were reduced when rapamycin was introduced [66].

\section{Neurofibromatosis types 1 and 2}

Neurofibromatosis is an autosomal dominant genetic disorder that is further classified into subtypes 1 and 2 . Neurofibromatosis types 1 and 2 are caused by inactivating mutations in NF1 and NF2 genes, respectively [67]. The loss of NF1 encodes for the protein neurofibromin and results in development of neurofibromas on or around peripheral nerves, along with pigmented tumors of the skin and iris [67]. Plexiform neurofibroma occur in up to one-third of individuals with neurofibromatosis type 1 and can cause disfigurement, compression of other bodily structures, neurologic dysfunction, and pain [68]. Evidence suggests that neurofibromin is involved in negatively regulating the mTOR pathway. A phase 2 study involving patients with progressive plexiform neurofibromas treated with sirolimus showed a modestly increased time to progression [68]. However, a similar phase 2 study that evaluated sirolimus with nonprogressive plexiform neurofibromas showed that sirolimus did not cause any tumor shrinkage [69]. A case series involving patients with symptomatic plexiform neurofibromas showed that, although sirolimus did not shrink tumor volume, pain was alleviated [70]. The lack of an antitumor response with sirolimus in neurofibromatosis type 1 may be caused by alternative compensatory mechanisms (e.g., feedback activation of Akt activity) following mTOR inhibition [71].

Neurofibromatosis type 2, the rarer of the two subtypes, involves the loss of the NF2 gene, which encodes for the regulator protein merlin. The loss of merlin leads to development of benign tumors called schwannomas, which can grow along auditory nerves, leading to hearing loss, and can compress nerves, leading to increased intracranial pressure, nerve dysfunction, and pain [67]. Similar to neurofibromin, merlin has been found to be a negative regulator of the mTOR pathway [72]. Rapamycin arrested schwannoma tumor growth in mice and in an in vitro model [72]. However, in a phase 2 study evaluating everolimus in the treatment of progressive vestibular schwannomas, none of the patients experienced a response ( $\geq 15 \%$ reduction in tumor volume) [73]. The activation of negative feedback loops following mTOR inhibition may also explain the limited efficacy of everolimus in vestibular schwannomas [73].

\section{Safety considerations with mTOR inhibition with TSC}

Current research strongly suggests that mTOR inhibition, particularly with everolimus, seems to remain effective and safe over extended duration of treatment for certain TSC manifestations. However, adverse events (AEs) considered to be class effects of mTOR inhibitors should be taken into consideration when using sirolimus or everolimus, including noninfectious pneumonitis, infections, oral ulceration (e.g., stomatitis), impaired wound healing, and metabolic events (e.g., hyperglycemia, dyslipidemia) $[39,51]$. These AEs may be appropriately managed by dose interruption or adjustment depending on severity of the event [39]. While long-term data on sirolimus in the TSC setting are lacking, clinical experience with everolimus in patients with TSC and renal angiomyolipoma or SEGA indicate that long-term everolimus therapy is generally well tolerated, with no new safety signals and the majority of AEs being mild to moderate in severity [36-38, 43, 74, 75].

\section{Long-term mTOR inhibition in TSC}

Although mTOR inhibitors are being investigated for the previously mentioned novel indications simply as a possible treatment option at this stage, the use of mTOR inhibitors in TSC has already been established and necessitates further investigation into the effects of longterm treatment.

TSC is a lifelong condition that can manifest itself at a very early age, and it is possible that patients, including children, will need indefinite treatment with an mTOR inhibitor. Some of the later manifestations of TSC may be alleviated or prevented by early treatment with an mTOR inhibitor; however, initiation of therapy in children and young adolescents may have other consequences as well. Therefore, it is important to discuss the efficacy and safety of mTOR inhibitor treatment in youth and its potential long-term effects on growth and maturation.

If patients are to undergo mTOR treatment long-term, sustainability of response is important. The recent longterm data from EXIST-1 [38] and EXIST-2 [43] showed a sustained and more pronounced clinical benefit of everolimus compared with the shorter-term, primary analyses $[35,40]$. Alternatively, in a subset of evaluable patients from EXIST-2 who were followed after discontinuation of everolimus $(n=7)$, angiomyolipoma lesion volume increased by more than $50 \%$ between everolimus discontinuation and 48 weeks after treatment [76]. These findings underscore the necessity of sustained treatment in TSC.

Although data on long-term exposure of mTOR inhibitors in youth, including effects on patient growth and sexual maturation, are limited, the EXIST-1 study reported that everolimus had no significant effect on puberty or development in patients with TSC after a median exposure of 47 months [38]. In addition, a retrospective analysis in a renal transplant population in which mTOR inhibitors were also used examined a cohort of 31 patients and reported that long-term mTOR therapy had no impact on growth and pubertal development after a mean follow-up 
of 4.9 years [77]. Further planned follow-up of the EXIST1 population may provide additional evidence of the effect of everolimus on growth and sexual maturation in the youth population.

\section{Conclusions and future directions}

Recent research in TSC has underlined the value of pursuing targeted therapies based on underlying molecular pathophysiology. TSC serves as a model for modification of acquired and inherited genetic defects causing brain dysfunction. A goal of current research is to identify the role of MTOR inhibition in neurologic and developmental disorders beyond that of TSC (e.g., Leigh syndrome, Down syndrome, and neurofibromatosis types 1 and 2), which nonetheless share a common feature of mTOR pathway hyperactivation. A better understanding of the molecular pathology of these seemingly diverse inherited and acquired brain diseases is necessary to achieve this goal. The recruitment of and performance of patients in basic science and particularly clinical studies is also a major challenge. However, available results in these areas show promise that, after further research, mTOR inhibition may eventually become a therapy option for these neurologic disorders where few options are currently available.

In addition to furthering research of mTOR inhibition in rare neurologic disorders, future research will also focus on defining the optimal use of mTOR inhibitors in TSC, including dosages for short- and long-term use, as well as age at which to initiate therapy. There has been longstanding interest in identifying treatment strategies for patients with TSC diagnosed at early ages where the potential effects of mTOR inhibitors or other therapies could drastically improve or even prevent the development of several TSC manifestations, including seizures, developmental delay, autism, renal disease, cutaneous tumors, and other lesions, by initiating treatment with mTOR inhibitors early in life. mTOR inhibitors are increasingly being used not only for the hamartomatous and oncologic manifestations of TSC, but also as adjunctive therapy for epilepsy and intellectual disability. Current research is expected to lead to a better definition of the roles of these therapies and their associated toxicities. As a result, the use of mTOR inhibition in TSC, including its use to prevent long-term morbidity, such as intellectual disability, autism, and refractory seizures, may be incorporated into clinical practice in the coming years.

\footnotetext{
Abbreviations

AE: Adverse event; Akt: Protein kinase B; ATP: Adenosine triphosphate; FDA: Food and Drug Administration; FEV F $_{1}$ Forced expiratory volume in $1 \mathrm{~s}$; FKBP12: FK506-binding protein-12; FVC: Forced vital capacity; IGF-1: Insulin-like growth factor-1; LAM: Lymphangioleiomyomatosis; mTOR: Mammalian target of rapamycin; PI3K: Phosphatidylinositol 3-kinase; RAPTOR: Regulatory associated protein of mTOR; Rheb: Ras homolog enriched in brain; RICTOR: Rapamycin-
}

insensitive companion of mTOR; SEGA: Subependymal giant cell astrocytoma; SEN: Subependymal nodule; TAND: TSC-associated neuropsychiatric disorders; TSC: Tuberous sclerosis complex; VEGF: Vascular endothelial growth factor

\section{Acknowledgements}

Medical editorial assistance was provided by Robert Schoen, PharmD, and Traci Stuve, MA, of ApotheCom (Yardley, PA, USA), with funding from Novartis Pharmaceuticals Corporation.

\section{Funding \\ Writing and editorial assistance for this manuscript was funded by Novartis Pharmaceuticals Corporation.}

\section{Availability of data and materials}

Data sharing is not applicable to this article as no datasets were generated or analyzed during the current study.

\section{Authors' contributions}

Dr. Franz and Dr. Capal contributed equally to the writing of this paper. Both authors read and approved the final manuscript.

\section{Competing interests}

DNF has received honoraria and travel support from Novartis and Lundbeck Pharmaceuticals. His institution, Cincinnati Children's Hospital Medical Center, has received research support and consulting fees from Novartis. JKC has nothing to disclose.

\section{Consent for publication}

Not applicable.

\section{Ethics approval and consent to participate}

Not applicable.

\section{Author details}

'Department of Pediatrics, Tuberous Sclerosis Clinic, Cincinnati Children's Hospital Medical Center, University of Cincinnati College of Medicine, Cincinnati, OH, USA. ²Department of Neurology, Tuberous Sclerosis Clinic, Cincinnati Children's Hospital Medical Center, University of Cincinnati College of Medicine, Cincinnati, OH, USA.

Received: 30 November 2016 Accepted: 14 February 2017

Published online: 14 March 2017

\section{References}

1. Franz DN. Everolimus: an mTOR inhibitor for the treatment of tuberous sclerosis. Expert Rev Anticancer Ther. 2011;11:1181-92.

2. Baskin Jr HJ. The pathogenesis and imaging of the tuberous sclerosis complex. Pediatr Radiol. 2008;38:936-52.

3. Curatolo P, Bombardieri R, Jozwiak S. Tuberous sclerosis. Lancet. 2008;372:657-68.

4. Osborne JP, Fryer A, Webb D. Epidemiology of tuberous sclerosis. Ann N Y Acad Sci. 1991;615:125-7.

5. Krueger DA, Northrup H. Tuberous sclerosis complex surveillance and management: recommendations of the 2012 International Tuberous Sclerosis Complex Consensus Conference. Pediatr Neurol. 2013;49:255-65.

6. Crino PB, Nathanson $\mathrm{KL}$, Henske EP. The tuberous sclerosis complex. N Engl J Med. 2006;355:1345-56.

7. Kwiatkowski DJ, Manning BD. Tuberous sclerosis: a GAP at the crossroads of multiple signaling pathways. Hum Mol Genet. 2005;14(spec no 2):R251-8.

8. Goh S, Butler W, Thiele EA. Subependymal giant cell tumors in tuberous sclerosis complex. Neurology. 2004;63:1457-61.

9. Adriaensen ME, Schaefer-Prokop CM, Stijnen T, Duyndam DA, Zonnenberg BA, Prokop M. Prevalence of subependymal giant cell tumors in patients with tuberous sclerosis and a review of the literature. Eur J Neurol. 2009:16:691-6.

10. Krueger DA. Management of CNS-related disease manifestations in patients with tuberous sclerosis complex. Curr Treat Options Neurol. 2013;15:618-33.

11. Thiele EA. Managing epilepsy in tuberous sclerosis complex. J Child Neurol. 2004;19:680-6.

12. Curatolo P. Mechanistic target of rapamycin (mTOR) in tuberous sclerosis complex-associated epilepsy. Pediatr Neurol. 2015;52:281-9.

13. Chu-Shore CJ, Major P, Camposano S, Muzykewicz D, Thiele EA. The natural history of epilepsy in tuberous sclerosis complex. Epilepsia. 2010;51:1236-41. 
14. Dragoumi P, Tzetzi O, Vargiami E, Pavlou E, Krikonis K, Kontopoulos E, et al. Clinical course and seizure outcome of idiopathic childhood epilepsy: determinants of early and long-term prognosis. BMC Neurol. 2013;13:206.

15. Shepherd CW, Gomez MR, Lie JT, Crowson CS. Causes of death in patients with tuberous sclerosis. Mayo Clin Proc. 1991;66:792-6.

16. McCormack FX. Lymphangioleiomyomatosis: a clinical update. Chest. 2008; 133:507-16.

17. Franz DN, Brody A, Meyer C, Leonard J, Chuck G, Dabora S, et al. Mutational and radiographic analysis of pulmonary disease consistent with lymphangioleiomyomatosis and micronodular pneumocyte hyperplasia in women with tuberous sclerosis. Am J Respir Crit Care Med. 2001;164:661-8.

18. Costello LC, Hartman TE, Ryu JH. High frequency of pulmonary lymphangioleiomyomatosis in women with tuberous sclerosis complex. Mayo Clin Proc. 2000;75:591-4.

19. Isaacs H. Perinatal (fetal and neonatal) tuberous sclerosis: a review. Am J Perinatol. 2009;26:755-60.

20. Yates JR. Tuberous sclerosis. Eur J Hum Genet. 2006;14:1065-73.

21. Jozwiak S, Kotulska K, Kasprzyk-Obara J, Domańska-Pakieła D, Tomyn-Drabik $M$, Roberts $P$, et al. Clinical and genotype studies of cardiac tumors in 154 patients with tuberous sclerosis complex. Pediatrics. 2006;118:e1146-51.

22. Schwartz RA, Fernandez G, Kotulska K, Jóźwiak S. Tuberous sclerosis complex: advances in diagnosis, genetics, and management. J Am Acad Dermatol. 2007;57:189-202

23. Orlova KA, Crino PB. The tuberous sclerosis complex. Ann N Y Acad Sci. 2010;1184:87-105

24. Yang H, Rudge DG, Koos JD, Vaidialingam B, Yang HJ, Pavletich NP. mTOR kinase structure, mechanism and regulation. Nature. 2013;497:217-23.

25. Mackeigan JP, Krueger DA. Differentiating the mTOR inhibitors everolimus and sirolimus in the treatment of tuberous sclerosis complex. Neuro Oncol. 2015;17:1550-9.

26. Johannessen CM, Reczek EE, James MF, Brems H, Legius E, Cichowski K. The NF1 tumor suppressor critically regulates TSC2 and mTOR. Proc Natl Acad Sci U S A. 2005;102:8573-8.

27. Wu J, Dombi $E_{1}$ Jousma E. Preclinical testing of sorafenib and RAD001 in the $N^{\text {flox/flox }}$;DhhCre mouse model of plexiform neurofibroma using magnetic resonance imaging. Pediatr Blood Cancer. 2012;58:173-80.

28. Costa-Mattioli M, Monteggia LM. mTOR complexes in neurodevelopmental and neuropsychiatric disorders. Nat Neurosci. 2013;16:1537-43.

29. Huang J, Manning BD. The TSC1-TSC2 complex: a molecular switchboard controlling cell growth. Biochem J. 2008;412:179-90.

30. Franz DN, Leonard J, Tudor C, Chuck G, Care M, Sethuraman G, et al. Rapamycin causes regression of astrocytomas in tuberous sclerosis complex. Ann Neurol. 2006;59:490-8

31. Koenig MK, Butler IJ, Northrup $H$. Regression of subependymal giant cell astrocytoma with rapamycin in tuberous sclerosis complex. J Child Neurol. 2008;23:1238-9.

32. Dabora SL, Franz DN, Ashwal S, Sagalowsky A, Dimario Jr FJ, Miles D, et al. Multicenter phase 2 trial of sirolimus for tuberous sclerosis: kidney angiomyolipomas and other tumors regress and VEGF-D levels decrease. Plos One. 2011;6:e23379.

33. Krueger DA, Care MM, Holland K, Agricola K, Tudor C, Mangeshkar P, et al. Everolimus for subependymal giant-cell astrocytomas in tuberous sclerosis. N Engl J Med. 2010;363:1801-11.

34. Krueger DA, Care MM, Agricola K, Tudor C, Mays M, Franz DN. Everolimus long-term safety and efficacy in subependymal giant-cell astrocytoma. Neurology. 2013:80:574-80.

35. Franz DN, Belousova E, Sparagana S, Bebin EM, Frost M, Kuperman R, et al. Efficacy and safety of everolimus for subependymal giant cell astrocytomas associated with tuberous sclerosis complex (EXIST-1): a multicentre, randomised, placebo-controlled phase 3 trial. Lancet. 2013;381:125-32.

36. Franz DN, Belousova E, Sparagana S, Bebin EM, Frost M, Kuperman R, et al. Everolimus for subependymal giant cell astrocytoma in patients with tuberous sclerosis complex: 2-year open-label extension of the randomised EXIST-1 study. Lancet Oncol. 2014;15:1513-20.

37. Franz DN, Agricola K, Mays M, Tudor C, Care MM, Holland-Bouley K, et al. Everolimus for subependymal giant cell astrocytoma: 5-year final analysis. Ann Neurol. 2015;78:929-38.

38. Franz DN, Belousova E, Sparagana S, Bebin EM, Frost MD, Kuperman R, et al. Long-term use of everolimus in patients with tuberous sclerosis complex: final results from the EXIST-1 study. Plos One. 2016;11:e0158476.
39. Novartis Pharmaceutical Corporation. Afinitor [package insert]. East Hanover: Novartis Pharmaceutical Corporation; 2016.

40. Bissler JJ, Kingswood JC, Radzikowska E, Zonnenberg BA, Frost M, Belousova E, et al. Everolimus for angiomyolipoma associated with tuberous sclerosis complex or sporadic lymphangioleiomyomatosis (EXIST-2): a multicentre, randomised, double-blind, placebo-controlled trial. Lancet. 2013:381:817-24.

41. Kingswood JC, Jozwiak S, Belousova ED, Frost MD, Kuperman RA, Bebin EM, et al. The effect of everolimus on renal angiomyolipoma in patients with tuberous sclerosis complex being treated for subependymal giant cell astrocytoma: subgroup results from the randomized, placebo-controlled, Phase 3 trial EXIST-1. Nephrol Dial Transplant. 2014;29:1203-10.

42. Bissler JJ, Kingswood JC, Radzikowska E, Zonnenberg BA, Frost M, Belousova E, et al. Everolimus for renal angiomyolipoma in patients with tuberous sclerosis complex or sporadic lymphangioleiomyomatosis: extension of a randomized controlled trial. Nephrol Dial Transplant. 2015:31:111-9.

43. Bissler JJ, Radzikowska E, Zonnenberg BA, Belousova E, Frost MD, Sauter M, et al. Everolimus for renal angiomyolipoma associated with tuberous sclerosis complex or sporadic lymphangioleiomyomatosis: final long-term results from EXIST-2. Munich: Presented at the 31st European Association of Urology (EAU) Annual Congress; 2016.

44. Bissler JJ, McCormack FX, Young LR, Elwing JM, Chuck G, Leonard JM, et al. Sirolimus for angiomyolipoma in tuberous sclerosis complex or lymphangioleiomyomatosis. N Engl J Med. 2008;358:140-51.

45. Davies DM, de Vries PJ, Johnson SR, McCartney DL, Cox JA, Serra AL, et al. Sirolimus therapy for angiomyolipoma in tuberous sclerosis and sporadic lymphangioleiomyomatosis: a phase 2 trial. Clin Cancer Res. 2011;17:4071-81.

46. Cabrera-Lopez C, Marti T, Catala V, Torres F, Mateu S, Ballarín J, et al. Assessing the effectiveness of rapamycin on angiomyolipoma in tuberous sclerosis: a 2 years trial. Orphanet J Rare Dis. 2012;7:87.

47. McCormack FX, Inoue Y, Moss J, Singer LG, Strange C, Nakata K, et al. Efficacy and safety of sirolimus in lymphangioleiomyomatosis. N Engl J Med. 2011:364:1595-606.

48. Ando K, Kurihara M, Kataoka $H$, Ueyama M, Togo S, Sato T, et al. The efficacy and safety of low-dose sirolimus for treatment of lymphangioleiomyomatosis. Respir Investig. 2013;51:175-83.

49. Yao J, Taveira-Dasilva AM, Jones AM, Julien-Williams P, Stylianou M, Moss J. Sustained effects of sirolimus on lung function and cystic lung lesions in lymphangioleiomyomatosis. Am J Respir Crit Care Med. 2014;190:1273-82.

50. Goldberg HJ, Harari S, Cottin V, Rosas IO, Peters E, Biswal S, et al. Everolimus for the treatment of lymphangioleiomyomatosis: a phase II study. Eur Respir J. 2015;46:783-94.

51. Wyeth Pharmaceuticals Inc., a subsidiary of Pfizer Inc. Rapamune [package insert]. Philadelphia: Wyeth Pharmaceuticals Inc; 2015.

52. Muncy J, Butler IJ, Koenig MK. Rapamycin reduces seizure frequency in tuberous sclerosis complex. J Child Neurol. 2009;24:477.

53. Canpolat M, Per H, Gumus H, Yikilmaz A, Unal E, Patiroglu T, et al. Rapamycin has a beneficial effect on controlling epilepsy in children with tuberous sclerosis complex: results of 7 children from a cohort of 86 . Childs Nerv Syst. 2014:30:227-40.

54. Cardamone M, Flanagan D, Mowat D, Kennedy SE, Chopra M, Lawson JA. Mammalian target of rapamycin inhibitors for intractable epilepsy and subependymal giant cell astrocytomas in tuberous sclerosis complex. J Pediatr. 2014:164:1195-200.

55. Overwater IE, Reitman AB, Bindels-De Heus K, Looman CW, Rizopoulos D, Sibindi TM, et al. Sirolimus for epilepsy in children with tuberous sclerosis complex: a randomized controlled trial. Neurology. 2016;87:1011-8.

56. Krueger DA, Wilfong AA, Holland-Bouley K, Anderson AE, Agricola K, Tudor $C$, et al. Everolimus treatment of refractory epilepsy in tuberous sclerosis complex. Ann Neurol. 2013;74:679-87.

57. French JA, Lawson JA, Yapici Z, Ikeda H, Polster T, Nabbout R, et al. Adjunctive everolimus therapy for treatment-resistant focal-onset seizures associated with tuberous sclerosis (EXIST-3): a phase 3, randomised, doubleblind, placebo-controlled study. Lancet. 2016;388:2153-63.

58. Schneider M, de Vries PJ, Schonig K, Rößner V, Waltereit R. mTOR inhibitor reverses autistic-like social deficit behaviours in adult rats with both Tsc2 haploinsufficiency and developmental status epilepticus. Eur Arch Psychiatry Clin Neurosci. 2016 Jun 4. [Epub ahead of print]. doi:10.1007/ s00406-016-0703-8

59. Hwang SK, Lee JH, Yang JE, Lim CS, Lee JA, Lee YS, et al. Everolimus improves neuropsychiatric symptoms in a patient with tuberous sclerosis carrying a novel TSC2 mutation. Mol Brain. 2016;9:56. 
60. Ruhoy IS, Saneto RP. The genetics of Leigh syndrome and its implications for clinical practice and risk management. Appl Clin Genet. 2014;7:221-34.

61. Johnson SC, Yanos ME, Kayser EB, Quintana A, Sangesland M, Castanza A, et al. mTOR inhibition alleviates mitochondrial disease in a mouse model of Leigh syndrome. Science. 2013;342:1524-8.

62. Zheng X, Boyer L, Jin M, Kim Y, Fan W, Bardy C, et al. Alleviation of neuronal energy deficiency by mTOR inhibition as a treatment for mitochondriarelated neurodegeneration. Elife. 2016;23:5.

63. Troca-Marin JA, Alves-Sampaio A, Montesinos ML. Deregulated mTOR-mediated translation in intellectual disability. Prog Neurobiol. 2012;96:268-82.

64. Troca-Marin JA, Alves-Sampaio A, Montesinos ML. An increase in basal BDNF provokes hyperactivation of the Akt-mammalian target of rapamycin pathway and deregulation of local dendritic translation in a mouse model of Down's syndrome. J Neurosci. 2011;31:9445-55.

65. Perluigi M, Pupo G, Tramutola A, Cini C, Coccia R, Barone E, et al. Neuropathological role of PI3K/Akt/mTOR axis in Down syndrome brain. Biochim Biophys Acta. 2014;1842:1144-53.

66. Tramutola A, Lanzillotta C, Arena A, Barone E, Perluigi M, Di Domenico F. Increased Mammalian Target of Rapamycin Signaling Contributes to the Accumulation of Protein Oxidative Damage in a Mouse Model of Down's Syndrome. Neurodegener Dis. 2016;16:62-8.

67. Gerber PA, Antal AS, Neumann NJ, Homey B, Matuschek C, Peiper M, et al. Neurofibromatosis. Eur J Med Res. 2009;14:102-5.

68. Weiss B, Widemann BC, Wolters P, Dombi E, Vinks A, Cantor A, et al. Sirolimus for progressive neurofibromatosis type 1-associated plexiform neurofibromas: a Neurofibromatosis Clinical Trials Consortium phase II study. Neuro Oncol. 2015;17:596-603.

69. Weiss B, Widemann BC, Wolters P, Dombi E, Vinks AA, Cantor A, et al. Sirolimus for non-progressive NF1-associated plexiform neurofibromas: an NF Clinical Trials Consortium phase II study. Pediatr Blood Cancer. 2014;61:982-6.

70. Hua C, Zehou O, Ducassou S, Minard-Colin V, Hamel-Teillac D, Wolkenstein $P$, et al. Sirolimus improves pain in NF1 patients with severe plexiform neurofibromas. Pediatrics. 2014:133:e1792-7.

71. James MF, Han S, Polizzano C, Plotkin SR, Manning BD, StemmerRachamimov AO, et al. NF2/merlin is a novel negative regulator of MTOR complex 1, and activation of mTORC1 is associated with meningioma and schwannoma growth. Mol Cell Biol. 2009:29:4250-61.

72. Giovannini M, Bonne NX, Vitte J, Chareyre F, Tanaka K, Adams R, et al. mTORC1 inhibition delays growth of neurofibromatosis type 2 schwannoma. Neuro Oncol. 2014;16:493-504.

73. Karajannis MA, Legault G, Hagiwara M, Giancotti FG, Filatov A, Derman A, et al. Phase II study of everolimus in children and adults with neurofibromatosis type 2 and progressive vestibular schwannomas. Neuro Oncol. 2014:16:292-7.

74. Bissler JJ, Kingswood JC, Radzikowska E, Zonnenberg BA, Frost M, Belousova $E$, et al. Everolimus for renal angiomyolipoma in patients with tuberous sclerosis complex or sporadic lymphangioleiomyomatosis: extension of a randomized controlled trial. Nephrol Dial Transplant. 2016:31:111-9.

75. Jozwiak S, Kotulska K, Berkowitz N, Brechenmacher T, Franz DN. Safety of everolimus in patients younger than 3 years of age: results from EXIST-1, a randomized, controlled clinical trial. J Pediatr. 2016;172:151-5.

76. Bissler JJ, Nonomora N, Budde K, Zonnenberg BA, Fischereder M, Berkowitz $\mathrm{N}$, et al. Evaluation of angiomyolipoma tumor behavior after termination of everolimus treatment: results of a subanalysis from EXIST-2. Vienna: Presented at the European Renal Association - European Dialysis and Transplantation (ERA-EDTA) 53rd Congress; 2016

77. Kranz B, Wingen AM, Vester U, König J, Hoyer PF. Long-term side effects of treatment with $\mathrm{mTOR}$ inhibitors in children after renal transplantation. Pediatr Nephrol. 2013;28:1293-8.

\section{Submit your next manuscript to BioMed Central and we will help you at every step:}

- We accept pre-submission inquiries

- Our selector tool helps you to find the most relevant journal

- We provide round the clock customer support

- Convenient online submission

- Thorough peer review

- Inclusion in PubMed and all major indexing services

- Maximum visibility for your research

Submit your manuscript at www.biomedcentral.com/submit
Biomed Central 